\title{
Modeling of DFIG-based Wind Farms for SSR Analysis
}

\author{
Lingling Fan, Senior Member, IEEE, Rajesh Kavasseri, Senior Member, IEEE, Zhixin Miao, Senior Member, \\ IEEE, Chanxia Zhu
}

\begin{abstract}
This paper presents a model for analysis and simulation of subsynchronous resonance (SSR) in series compensated systems with Doubly Fed Induction Generator (DFIG) based wind farms. The model is used to analyze the induction generator effect (IGE) and torsional interaction in such systems. A test system based on the IEEE first benchmark model is considered for the analysis. The effect of three factors namely: i) series compensation level, ii) wind speed, and iii) current loop gains on the IGE and TI are studied. Small signal (eigenvalue) analysis is conducted to assess the damping of network and torsional modes followed by dynamic (time domain) simulations.
\end{abstract}

Index Terms-Doubly Fed Induction Generator, SSR, Induction Generator Effect, Torsional Interaction

\section{INTRODUCTION}

The phenomenon of SSR has been well studied in series compensated systems with synchronous generators [1], [2]. SSR is divided into three groups: induction generator effect (IGE), torsional interaction (TI), and torsional amplification [2]. The first two denote phenomena related with steady state and the third denotes a transient phenomenon. While IGE involves interactions between the electrical network and the generator solely, torional interactions include mechanical dynamics introduced by turbines.

Given the proliferation of wind farms, a natural question is whether SSR can manifest in series compensated wind farms. A vast majority of wind farms in operation are based on induction generators. SSR phenomena (excluding shaft dynamics) in single-cage induction motors was discussed in an early work [3] by Limebeer and Harley. In [3], it is shown that instability is due to the effective resistance at the machine terminals being negative under subsynchronous frequency. In another words, SSR phenomenon in induction machines is primarily due to IGE.

A recent paper [4] investigates SSR in series compensated fixed speed wind generation systems that employ self excited double cage induction generators. PSCAD simulations are conducted to demonstrate IGE and TI. The paper concludes that the greater the output power from wind farms, the lesser the system damping. However, variable speed wind generation systems employing DFIG offer greater operational

L. Fan, Z. Miao and C. Zhu are with Dept. of Electrical Engineering, University of South Florida, Tampa FL 33620. Emails: linglingfan@eng.usf.edu, zmiao@eng.usf.edu, chanxia@mail.usf.edu. R. Kavasseri is with Dept. of Electrical \& Computer Engineering, North Dakota State University, Fargo, ND 58105. Email: Rajesh.Kavasseri@ndsu.edu. flexibility and improved efficiencies and hence, are rapidly gaining ground as opposed to fixed speed systems. A recent work [5] presents the modeling and stability of a DFIG-based wind farm interfaced with series compensation. Impact of parameters such as wind speed, compensation level and current controller parameters on system damping under subsynchronous frequency are studied. However, [5] does not classify if the instability is caused by IGE or TI.

Thus the focus in this paper is to systematically examine SSR in DFIG based series compensated systems. While a preliminary analysis appears in [6], detailed analysis is carried out in this paper to identify under what parametric conditions the IGE and torsional interactions manifest. The system models in this paper are developed in MATLAB/Simulink for ease of small signal analysis as well as time domain simulations. However, other tools such as PSCAD/EMTDC [7] or ATP/EMTP [8] have also been used for time domain SSR simulations.

The rest of the paper is organized as the follows. Section II presents the background for SSR analysis in DFIG systems. Section III presents the study system and the dynamic models for the DFIG (with converter interface), the series compensated network and the torsional dynamics. Sections IV and V present the small signal analysis with time domain simulations results for induction generator effect and torsional interactions respectively. Section VI concludes the paper.

\section{ANALYSIS OF SSR IN A DFIG}

A series-compensated network has a natural resonant frequency $\left(f_{n}\right)$ given by $f_{n}=f_{0} \sqrt{\frac{X_{c}}{X_{L}}} \mathrm{~Hz}$ (where $f_{0}$ is the synchronous frequency in $\mathrm{Hz}$ ). At this subsynchronous frequency $f_{n}$, the slip $s_{1}$ is given by:

$$
s_{1}=\frac{f_{n}-f_{m}}{f_{n}}
$$

where $f_{m}$ is the electric frequency corresponding to the rotating speed. Since $f_{n}$ is usually less than $f_{m}, s_{1}<0$. From the steady state equivalent circuit for a DFIG (shown in Fig. 1), the equivalent rotor resistance at subsynchronous frequency is negative or $R_{r, e q}=R_{r} / s_{1}<0$. If the magnitude of this resistance exceeds the resistance of the armature plus network, the system has a negative resistance at the subsynchronous frequency. This can result in self-excitation leading to sustained or oscillatorily growing armature currents. 
This phenomenon is known as the IGE [2].

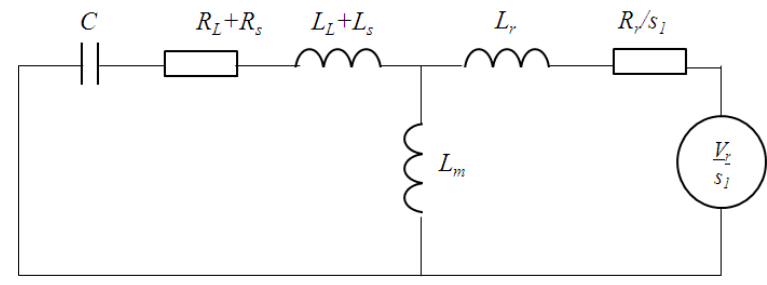

Fig. 1. The equivalent circuit under subsynchronous frequency.

Table I shows the frequency relationships in a DFIG. Due of series-compensation, a subsynchronous component in voltages and currents with a frequency of $f_{n}$ is introduced to the network and the stator circuit of a DFIG. The complementary frequency of this component in rotor current is $\left(f_{s}-f_{n}\right)$. From Table I, the stator currents have two components $\left(I_{s 1}\right.$ and $\left.I_{s 2}\right)$ and the rotor currents also have two components $\left(I_{r 1}\right.$ and $\left.I_{r 2}\right) . I_{s 1}$ is at nominal frequency $f_{s}$ and $I_{s 2}$ is at resonant frequency $f_{n} . I_{r 1}$ and $I_{r 2}$ are their corresponding rotor current components. These currents will have interactions to produce torque, which is shown in Table II, where $T_{1}$ is due to the interaction of $I_{s 1}$ and $I_{r 1}, T_{2}$ is due to the interaction of $I_{s 1}$ and $I_{r 2}, T_{3}$ is due to the interaction of $I_{s 2}$ and $I_{r 1}$ and $T_{4}$ is due to the interaction of $I_{s 2}$ and $I_{r 2}$.

Thus the torque will have a component at frequency of $f_{s}-f_{n}$ due to the network series compensation. Torsional interactions result when the frequency of the torsional mode $f_{T I}$ is close or coincides with the complementary frequency $f_{s}-f_{n}$.

TABLE I

FREQUENCY RELATIONSHIPS OF THE DFIG

\begin{tabular}{|c|c|c|}
\hline Stator current & $f_{s}\left(I_{s 1}\right)$ & $f_{n}\left(I_{s 2}\right)$ \\
\hline Rotating shaft speed & $f_{m}$ & $f_{m}$ \\
\hline Rotor current & $\left(f_{s}-f_{m}\right)\left(I_{r 1}\right)$ & $\left(f_{n}-f_{m}\right)\left(I_{r 2}\right)$ \\
\hline
\end{tabular}

TABLE II

TORQUE COMPONENTS

\begin{tabular}{|c|c|c|c|c|}
\hline Torque comp. & $T_{1}$ & $T_{2}$ & $T_{3}$ & $T_{4}$ \\
\hline Interaction & $I_{s 1} \& I_{r 1}$ & $I_{s 1} \& I_{r 2}$ & $I_{s 2} \& I_{r 1}$ & $I_{s 2} \& I_{r 2}$ \\
\hline Frequency & 0 & $f_{s}-f_{n}$ & $f_{s}-f_{n}$ & 0 \\
\hline
\end{tabular}

The IGE is principally dependent on the slip $s_{1}$. The slip $s_{1}$ (from (1)) is influenced by wind speed and compensation level (from 1). In addition, current control schemes which are used to obtain the rotor voltage injections can have impact on the equivalent rotor resistance $R_{r, e q}$ (from Fig. 1). The effect of these parametric variations on SSR phenomena is studied using the models developed in the following section.

\section{SYSTEM MODEL}

The study system is shown in Fig. 2 where a DFIG-based wind farm (892.4 MVA from aggregation of 2 MW units) is connected to a series-compensated line whose parameters correspond to the IEEE first benchmark model for SSR studies
[9]. The wind farms can be considered as coherent generators and can be represented by one large DFIG. This approach has been practiced in system studies [10]. The parameters are: $R_{L}=0.02 \mathrm{pu}, X_{L}=0.5 \mathrm{pu}, X_{T}=0.14 \mathrm{pu}$ and $X_{T g}=0.3 \mathrm{pu}$.

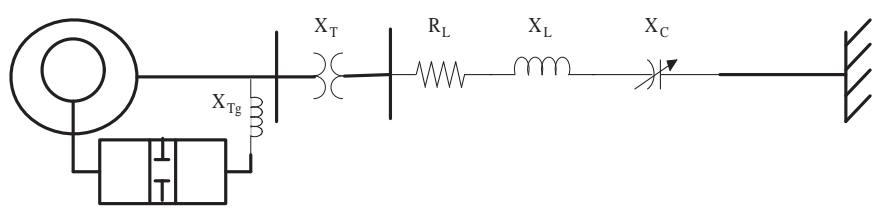

Fig. 2. The study system.

\section{A. Series compensation network model}

Synchronous reference frame is widely used for modeling induction machines [11]. The same reference frame should be adopted for the network model. In the synchronous reference frame, the dynamics of the series compensated system can be described by:

$$
\begin{aligned}
\frac{d}{d t}\left[\begin{array}{c}
v_{c q} \\
v_{c d} \\
i_{q} \\
i_{d}
\end{array}\right] & =\omega_{B}\left[\begin{array}{cccc}
0 & -\omega_{e} & X_{c} & 0 \\
\omega_{e} & 0 & 0 & X_{c} \\
\frac{-1}{X_{L}} & 0 & -\frac{R_{L}}{X_{L}} & -\omega_{e} \\
0 & \frac{-1}{X_{L}} & \omega_{e} & -\frac{R_{L}}{X_{L}}
\end{array}\right]\left[\begin{array}{c}
v_{c q} \\
v_{c d} \\
i_{q} \\
i_{d}
\end{array}\right] \\
& +\omega_{B}\left[\begin{array}{c}
0 \\
0 \\
\frac{v_{t q}-E_{B q}}{X_{L}} \\
\frac{v_{t d}-E_{B d}}{X_{L}}
\end{array}\right] .
\end{aligned}
$$

where $v_{c q}$ and $v_{c d}$ are the quadrature and direct axis voltages across the capacitor, $i_{q}$ and $i_{d}$ are the quadrature and direct axis current through the transmission line, $v_{t q}$ and $v_{t d}$ are the quadrature and direct axis voltages of the terminal bus, $E_{B q}$ and $E_{B d}$ are the quadrature and direct axis voltages of the infinite bus, $\omega_{B}$ is the base speed ( $\left.377 \mathrm{rad} / \mathrm{s}\right)$ and $\omega_{e}$ is the synchronous reference frame speed $(377 \mathrm{rad} / \mathrm{s})$. Note that network resonance at $f_{n}$ will be observed as an oscillation mode with a complimentary frequency $f_{s}-f_{n}$ due to the synchronous reference frame. The state variables associated with the network are denoted by $X_{n}$

$$
X_{n}=\left[v_{c q}, v_{c d}, i_{q}, i_{d}\right] .
$$

\section{B. Induction generator model}

A 6th order dynamic model [12] is used for the DFIG with rotor side converter. The model is described by:

$$
\dot{X}_{g}=A X_{g}+B U
$$

where

$$
\begin{aligned}
X_{g} & =\left[i_{q s}^{e}, i_{d s}^{e}, i_{o s}^{e}, i_{q r}^{\prime e}, i_{d r}^{\prime e}, i_{0 r}^{\prime e}\right]^{T} \\
U & =\left[v_{q s}^{e}, v_{d s}^{e}, v_{0 s}^{e}, v_{q r}^{\prime e}, v_{d r}^{\prime e}, v_{0 r}^{\prime e}\right]^{T} .
\end{aligned}
$$

The expressions of $A, B$ are listed in the Appendix. 


\section{DC link model}

The dynamics of the capacitor in the dc link between the rotor and stator side converters are described by a first order model:

$$
\begin{aligned}
C v_{c} \frac{d v_{c}}{d t} & =P_{r}-P_{g} \\
P_{r} & =\frac{1}{2}\left(v_{q r} i_{q r}+v_{d r} i_{d r}\right) \\
P_{g} & =\frac{1}{2}\left(v_{q g} i_{q g}+v_{d g} i_{d g}\right)
\end{aligned}
$$

Constant voltage source model is assumed for the grid side converter (GSC) of the DFIG to simplify the analysis in this paper.

\section{Torsional dynamics model}

A two-mass system [1], [13] is used to the represent torsional dynamics given by:

$$
\begin{aligned}
\frac{d}{d t}\left[\begin{array}{c}
\Delta \omega_{t} \\
\Delta \omega_{r} \\
T_{g}
\end{array}\right] & =\left[\begin{array}{ccc}
\frac{-D_{t}-D_{t g}}{2 H_{t}} & \frac{D_{t g}}{2 H_{t}} & \frac{-1}{2 H_{t}} \\
\frac{D_{t g}}{2 H_{g}} & \frac{-D_{g}-D_{t g}}{2 H_{g}} & \frac{1}{2 H_{g}} \\
K_{t g} \omega_{e} & -K_{t g} \omega_{e} & 0
\end{array}\right]\left[\begin{array}{c}
\Delta \omega_{t} \\
\Delta \omega_{r} \\
T_{g}
\end{array}\right] \\
+ & {\left[\begin{array}{c}
\frac{T_{m}}{2 H_{t}} \\
\frac{-T_{e}}{2 H_{g}} \\
0
\end{array}\right] . }
\end{aligned}
$$

where $\omega_{t}$ and $\omega_{r}$ are the turbine and generator rotor speed, respectively; $P_{m}$ and $P_{e}$ are the mechanical power of the turbine and the electrical power of the generator, respectively; $T_{g}$ is an internal torque of the model; $H_{t}$ and $H_{g}$ are the inertia constants of the turbine and the generator, respectively; $D_{t}$ and $D_{g}$ are the mechanical damping coefficients of the turbine and the generator, respectively; $D_{t g}$ is the damping coefficient of the flexible coupling (shaft) between the two masses; $K_{t g}$ is the shaft stiffness. The state variables associated with the torsional dynamics are denoted by $X_{t}$

$$
X_{t}=\left[\Delta \omega_{t}, \Delta \omega_{r}, T_{g}\right]
$$

The entire system model (14th order) described by:

$$
\dot{X}=f(X, U)
$$

where $X=\left[X_{n}, X_{g}, v_{c}, X_{t}\right]$ is assembled in Matlab/Simulink. Eigenvalue analysis and time domain simulations obtained with this model are described next.

\section{Results of Induction Generator EFFECT}

\section{A. Impact of wind speed and compensation level on SSR}

The damping of the network resonant mode for different wind speeds are shown in Fig. 3. The results indicate that the damping of this mode improves with increasing wind speeds (and thus higher output powers). This is explained as follows. For a given wind speed, the optimal turbine rotational speed $\left(f_{m}\right)$ is computed from the maximum power tracking scheme to maximize power extraction. When the wind speed decreases, this rotating speed $f_{m}$ will decrease which in turn decreases the magnitude of slip $s_{1}$. Thus $s_{1}$ is dependent on wind speed. Therefore, the equivalent rotor resistance $R_{r, e q}$ assumes a larger negative value and worsens the damping of this mode. The converse is true with increasing wind speeds. Fig. 4 shows the relationship between the equivalent rotor resistance and the rotor speed. It is found that with higher wind speed, the higher $f_{m}$, hence $R_{r, e q}$ will be less negative. This feature is also noticeable from the dynamic response for two different wind speeds as shown in Fig. 6.

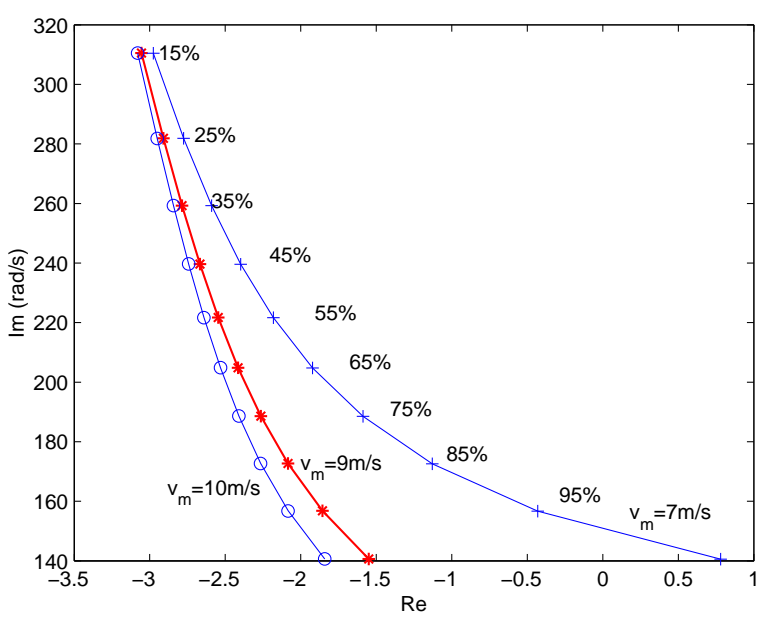

Fig. 3. The network resonance mode at various compensation level for different wind speed. The embedded figure shows the equivalent rotor resistance versus the rotor rotating speed at $85 \%$ compensation level.

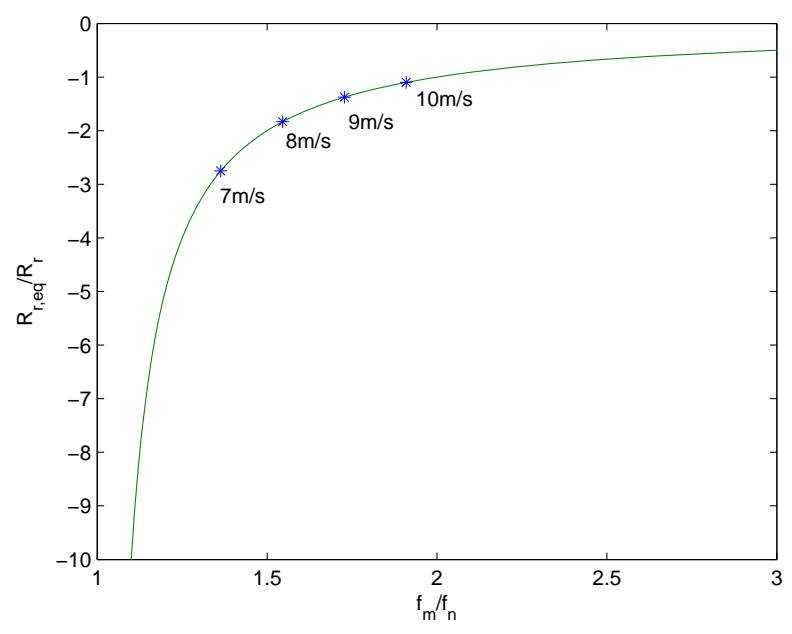

Fig. 4. The equivalent rotor resistance versus the rotor rotating speed at $85 \%$ compensation level.

To focus on the IGE, simulations are performed with the torsional system disabled. Fig. 5 shows the dynamic response with varying compensation levels at a fixed wind speed $(9 \mathrm{~m} / \mathrm{s})$. Fig. 6 shows the dynamic response with varying wind speeds at a fixed compensation level (75\%). The dynamic responses are initiated due to non-equilibrium initial conditions. It is also assumed that the rotor voltage injection is purely based on slip control. Observe from Fig. 5 that the higher the compensation level, the weaker the damping. From Fig. 6, the higher the wind speed, the better the SSR damping. This 
is in contrast to fixed speed systems where the damping of network mode worsens with increasing wind speeds. In fixed speed systems, the slip $s_{1}$ is independent of wind speed with $f_{m}$ being very close to the nominal frequency $f_{s}$. Thus the higher the wind power delivered to the system, the lower the resistance of the network as seen from the wind farm and hence the more unstable the mode as reported in [4].

With DFIG systems however, the damping of the network mode improves with increasing wind speeds as shown by the eigenvalue results in Fig. 3 and simulations in Fig. 6. To differentiate the simulation results, the line resistance is reduced from $0.02 \mathrm{pu}$ to $0.01 \mathrm{pu}$ in Fig. 6 . Thus, at $7 \mathrm{~m} / \mathrm{s}$ wind speed, the system becomes unstable due to the negative damping of the oscillation. At higher wind speed, the system is stable. These findings are consistent with the observation that the dominant mode tends to become more unstable as the wind speed decreases, [5].

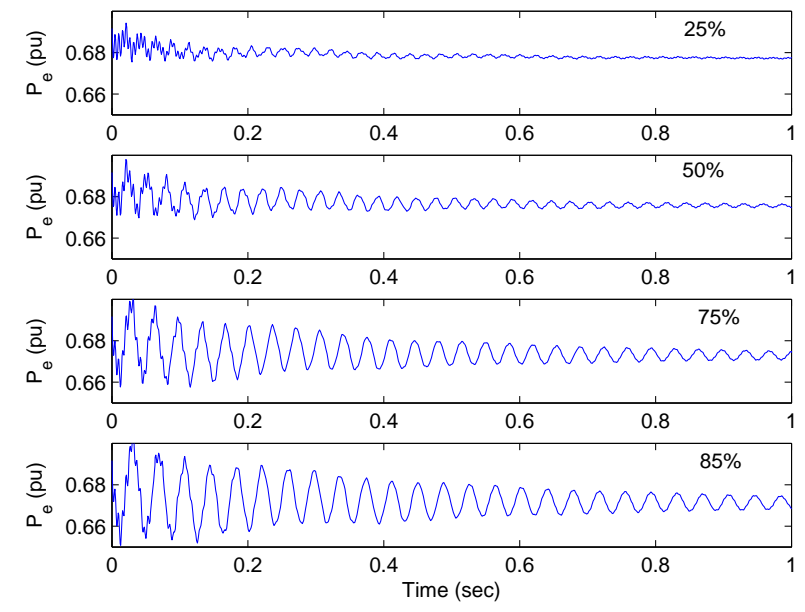

Fig. 5. Dynamic response of $P_{e}$ under different compensation level. Wind speeds: $9 \mathrm{~m} / \mathrm{s}$.

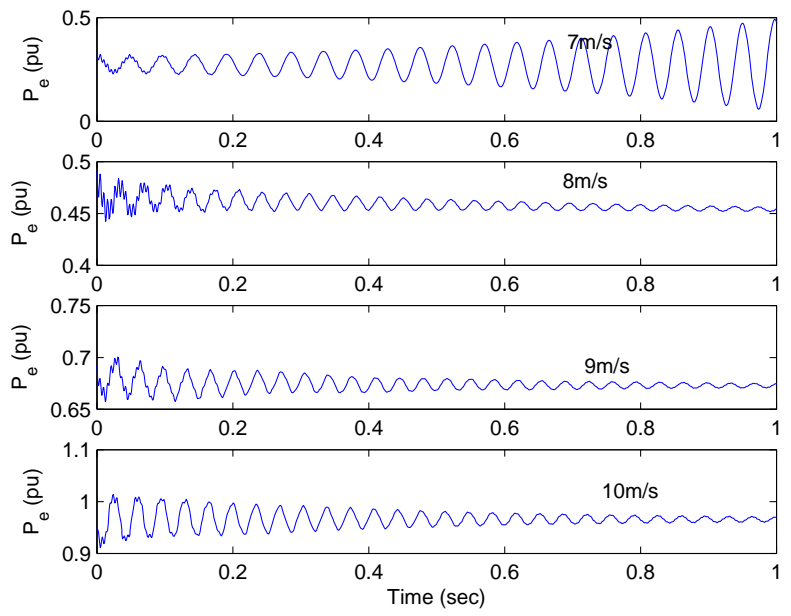

Fig. 6. Dynamic response of $P_{e}$ under different wind speeds. Compensation level: $75 \%$. Note: The line resistance is reduced from $0.02 \mathrm{pu}$ to $0.01 \mathrm{pu}$ in this set of simulation results to show instability at $7 \mathrm{~m} / \mathrm{s}$ wind speed.
From Fig. 3, increasing levels of series compensation (at a fixed wind speed) decrease the damping of the SSR mode. The higher the compensation, the higher the natural resonant frequency $f_{n}$, and hence closer $f_{n}$ will be to $f_{m}$. This will make the negative resistance have a larger magnitude and worsen the damping of the resonant modes [2].

\section{B. Impact of DFIG current controllers on SSR}

The rotor voltage injections in a DFIG are generated by current control loops in $q d$-axis as shown in Fig. 7 [12]. The reference current values are based on outer control loops for torque and voltage regulation [12]. In this paper, since current controllers are the focus of the investigation, for simplicity, the outer loops are not modeled. Further, the integral unit gain $K_{i}$ is set to zero. The effect of the proportional gain $K_{p}$ will be investigated.

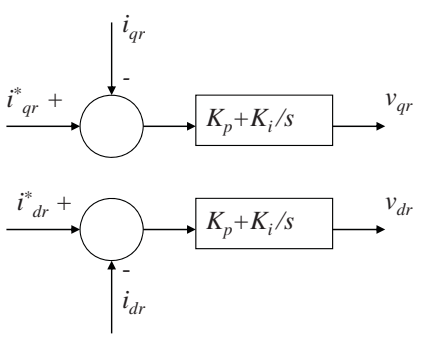

Fig. 7. Current loop for rotor side converters.

The effect of the proportional gains $\left(K_{p}\right)$ in these control loops, on the damping of SSR mode is computed by eigenvalue analysis as shown in Table III. The dynamic simulation results shown in Fig. 8 for $P_{e}$ at different gains show that increasing gains have a detrimental impact on the damping. This is explained as follows. The effect of a rotor voltage injection $\left(V_{r}=k I_{r}\right)$ is equivalent to a resistance $R=\frac{-V_{r}^{\prime} / s}{I_{r}}=-\frac{k}{s}$ in the rotor circuit. A positive resistance will improve system stability. Since the slip $s_{1}$ under SSR is negative, then the gain $k$ should be positive. However, in the DFIG current control schemes, negative feedback control loop is employed as shown in Fig. 7. Hence the current control loops cause detrimental impact on the damping.

TABLE III

IMPACT OF DFIG CURRENT CONTROLLERS ON SSR AT 75\% COMPENSATION LEVEL WITH WIND SPEED AT $10 \mathrm{M} / \mathrm{s}$

\begin{tabular}{|c|c|c|c|}
\hline \hline$K_{p}$ & Network Mode & $\mathrm{Hz}$ & Damping \\
\hline 0 & $-2.3 \pm j 180.6$ & 28.74 & $1.27 \%$ \\
0.1 & $9.8 \pm j 185.6$ & 29.54 & $-5.21 \%$ \\
0.5 & $16.5 \pm j 208.0$ & 33.10 & $-7.86 \%$ \\
\hline \hline
\end{tabular}

In order to keep the system from self-excitation, it is therefore necessary to keep the proportional gain of the current control loop in a range. Time-domain simulations are performed for various $K_{p}$ in Fig. 8 corroborate the results in Table III. 


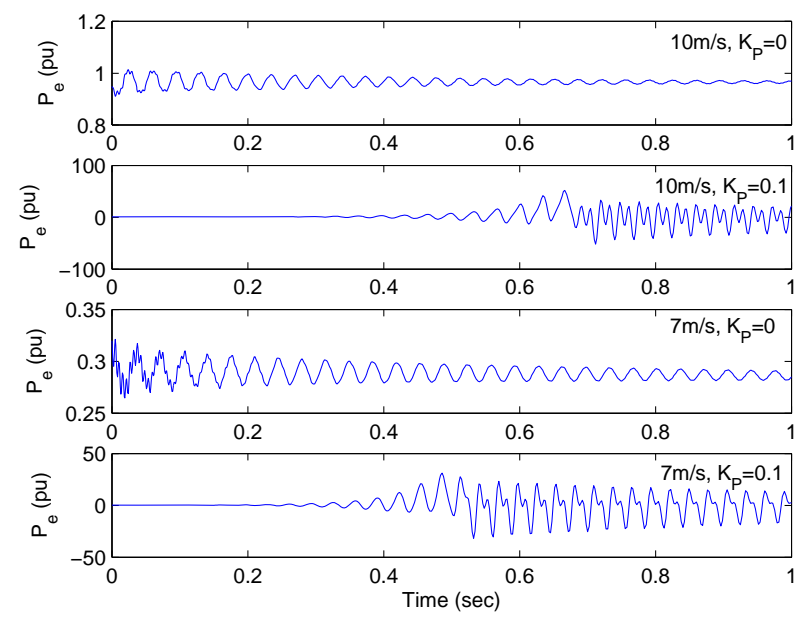

Fig. 8. Dynamic response of $P_{e}$ under different $K_{p}$. Compensation level: $75 \%$

\section{RESUlts OF TI EFFECT}

The oscillatory mode of the torsional dynamics depends greatly on shaft stiffness $K_{t g}$. Wind turbine shafts have small stiffness constants [14] compared to the drive trains for steam, hydro and diesel generators. In the GE report [10], a 3.6 MW DFIG has a $K_{t g}=3.6 \mathrm{pu}$ while in [4], this constant is set to $0.15 \mathrm{pu}$ for a $100 \mathrm{MW}$ drive train. The dependence of the torsional mode on shaft stiffness is tabulated in Table IV below.

TABLE IV

TORSIONAL MODES FOR VARIOUS STIFFNESS CONSTANT. WIND SPEED AT 9M/S AND COMPENSATION LEVEL AT 75\%.

\begin{tabular}{|c|c|c|}
\hline$K_{t g}$ & Eigenvalue & $f_{T I}(\mathrm{~Hz})$ \\
\hline 0.15 & $-2.69 \pm 31.74$ & 5.05 \\
1 & $-2.24 \pm 33.70$ & 5.36 \\
2 & $-1.81 \pm 36.26$ & 5.77 \\
3 & $-1.48 \pm 38.93$ & 6.20 \\
10 & $-0.74 \pm 56.19$ & 8.94 \\
50 & $-0.52 \pm 115.28$ & 18.35 \\
100 & $-0.35 \pm 162.45$ & 25.85 \\
150 & $-0.16 \pm 193.79$ & 30.84 \\
200 & $-0.49 \pm 225.42$ & 35.87 \\
250 & $-0.05 \pm 252.1$ & 40.12 \\
\hline
\end{tabular}

From Table IV, it is found that at normal range of $K_{t g}$, the frequency of torsional mode is less than $10 \mathrm{~Hz}$. The complimentary frequency will be larger than $50 \mathrm{~Hz}$ in a $60 \mathrm{~Hz}$ ac network. It is unusual for the network resonant frequency to exceed $50 \mathrm{~Hz}$, even at very high levels of compensation. Therefore torsional interactions are highly unlikely considering typical values of wind turbine shaft stiffness. For the sake of completeness and illustration, $K_{t g}$ is chosen to be $99.67 \mathrm{pu}$ (large) which results in a torsional oscillatory frequency at about $25 \mathrm{~Hz}$ and the complimentary frequency is $35 \mathrm{~Hz}$. If by increasing the compensation level, the network resonant frequency gets close to $35 \mathrm{~Hz}$, then TI is noticeable. In the following subsections, impact of compensation level and wind speed is demonstrated by both eigenvalue analysis and timedomain simulations.

\section{A. Impact of Compensation Level on Torsional Mode}

With the addition of two-mass shaft system, the combined shaft and generator system has two modes of oscillations. One is the oscillation of the entire rotor against the power system, the other is the torsional mode. When the torsional mode frequency $f_{T I}$ equals the complimentary of the network mode frequency $\left(f_{s}-f_{n}\right)$, the torsional interaction will occur [2]. When the series-compensation level is low, $f_{n}$ is low. The complimentary frequency is high. If the series compensation increases, then $f_{n}$ increases and the complimentary frequency decreases. Torsional interactions are noticeable when the frequency of the torsional mode is close or coincides with the complementary frequency $f_{s}-f_{n}$. Table $\mathrm{V}$ shows the torsional mode and the network mode with multi-mass representation of the DFIG-based wind turbine rotor. It is seen that $f_{T I}$ is fairly insensitive for compensation levels between $25 \%$ to $75 \%$. However, at $90 \%$ compensation, the mode is undamped (with frequency $25.29 \mathrm{~Hz}$ ) and the frequency of network mode is $25.21 \mathrm{~Hz}$. Therefore, there will be self excitation of SSR due to TI effect between the two modes. This is verified with the dynamic simulations shown in Fig. 9 where modal instability can be seen at the $90 \%$ compensation level. Note however that the oscillations are sustained. Additionally, the torsional mode becomes unstable (from $0.31 \%$ to $-3.27 \%$ ) while the damping of the network mode improves (from 1.07 $\%$ to $4.79 \%$ ). The locus of the torsional and network modes with various compensation levels are shown in Fig. 10 and Fig. 11 respectively.

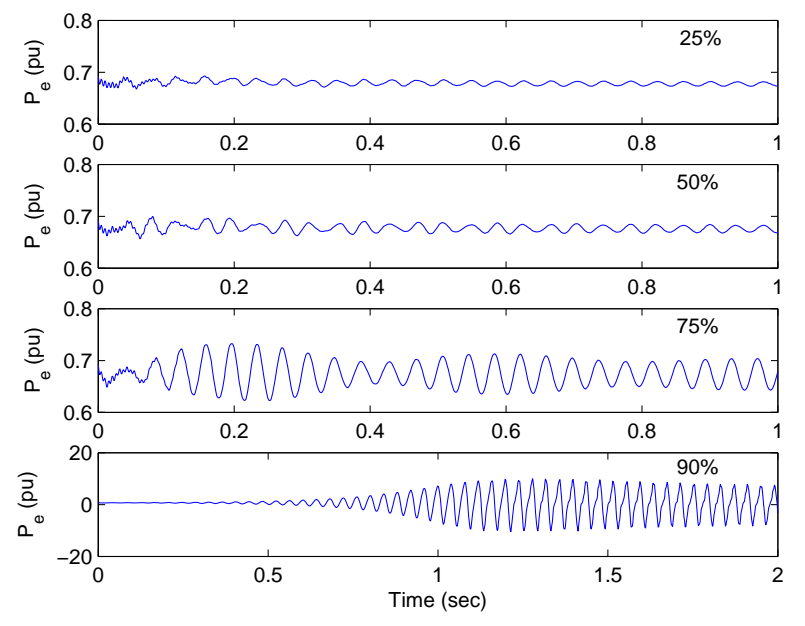

Fig. 9. Electrical torque with various series-compensated in multi-mass DFIG-based wind turbine system. TI effects are demonstrated in the $90 \%$ case. Wind speed at $9 \mathrm{~m} / \mathrm{s}$.

\section{B. Impact of wind speed on TI}

The variation of network and torional modes with wind speeds, at fixed compensation levels are shown in Table VI. In general, it can be noted that both the modes (in terms of frequency and damping) are fairly insensitive to changes in wind speed. This is explained as follows. The TI effect is due to the torsional dynamic oscillation at a frequency of $f_{T I}$. The 
TABLE V

COMPARISON OF THE TORSIONAL MODE AND NETWORK MODE AT VARIOUS SERIES-COMPENSATED LEVEL WITH MULTI-MASS REPRESENTATION OF THE DFIG-BASED WIND TURBINE ROTOR

\begin{tabular}{|c|c|c|c|c|c|c|}
\hline \multirow{2}{*}{$\%$ Comp. } & \multicolumn{3}{|c|}{ Torsional Mode } & \multicolumn{3}{c|}{ Network Mode } \\
\cline { 2 - 7 } & $\sigma \pm j \omega$ & $f_{T I}(H z)$ & $\xi$ & $\sigma \pm j \omega$ & $f_{s}-f_{n}(H z)$ & $\xi$ \\
\hline 25 & $-0.5 \pm j 160.4$ & 25.53 & $0.31 \%$ & $-2.9 \pm j 270$ & 42.97 & $1.07 \%$ \\
\hline 50 & $-0.5 \pm j 160.6$ & 25.56 & $0.31 \%$ & $-2.6 \pm j 221.3$ & 35.22 & $1.17 \%$ \\
\hline 75 & $-0.4 \pm j 162.2$ & 25.81 & $0.25 \%$ & $-2.3 \pm j 178.8$ & 28.46 & $1.29 \%$ \\
\hline 90 & $5.2 \pm j 158.9$ & 25.29 & $-3.27 \%$ & $-7.6 \pm j 158.4$ & 25.21 & $4.79 \%$ \\
\hline
\end{tabular}

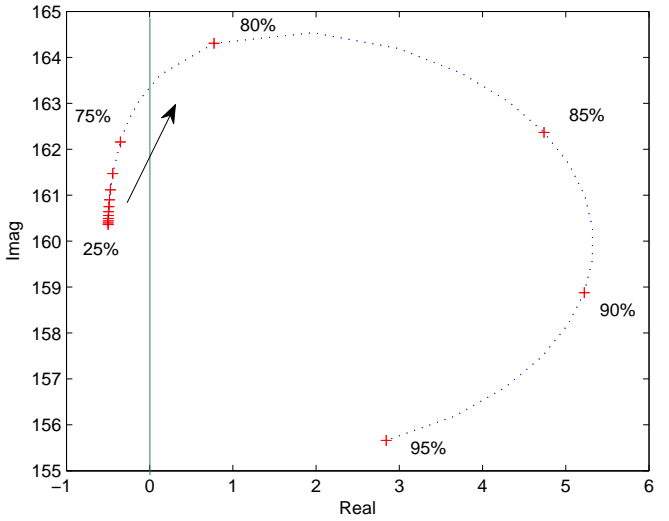

Fig. 10. Torsional mode in the $s$-plane.

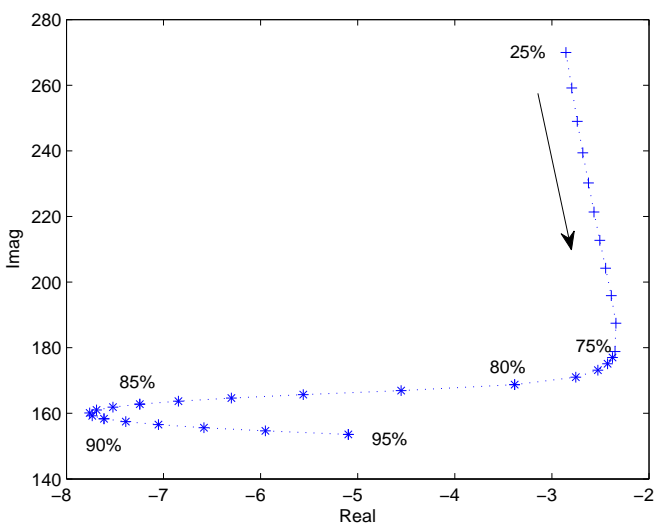

Fig. 11. Network mode in the $s$-plane.

network resonance frequency due to series compensation is $f_{n}$. When the wind speed varies, the slip of the DFIG varies. This slip has no direct link to $f_{T I}$ and $f_{n}$. Hence the wind speed has slight impact on SSR damping as shown in Table VI. Thus, the compensation level has a more significant impact on TI than the wind speed.

\section{CONClusions}

This paper presents a model for analysis and simulation of subsynchronous resonance (SSR) in series compensated systems with Doubly Fed Induction Generator (DFIG) based wind farms. The model is used to analyze the induction generator induction generator effect and torsional dynamics on test system based on the IEEE first benchmark model. Three factors namely: i) series compensation level, ii) wind speed, and iii) current loop gains, that impact both these phenomena are studied. The analysis is supported by eigenvalue computations and verified by dynamic simulations. Contrary to fixed speed systems, we find that the damping of network mode (influencing the IGE) improves with increasing wind speeds. Torsional interactions are found to result only for unusually high values of the staff shiftness unlikely to be encountered with wind turbines. Even with this consideration, in contrast, the damping of the torsional mode is found to be insensitive to wind speed variations. This suggests that the IGE primarily has a bearing for SSR studies in variable speed wind generation systems employing DFIGs.

\section{APPENDIX}

The voltage equations of an induction machine in a synchronous reference frame can be written in terms of the currents as shown in (6) [11].

The air gap flux linkages $\lambda_{q m}^{e}$ and $\lambda_{d m}^{e}$ can be expressed as:

$$
\begin{aligned}
& \lambda_{q m}^{e}=L_{M}\left(i_{q s}^{e}+i_{q r}^{\prime e}\right) \\
& \lambda_{d m}^{e}=L_{M}\left(i_{d s}^{e}+i_{d r}^{\prime e}\right)
\end{aligned}
$$

and the electromagnetic torque $T_{e}$ can be expressed as:

$$
\begin{gathered}
T_{e}=\lambda_{q m}^{e} i_{d r}^{e}-\lambda_{d m}^{e} i_{q r}^{e} . \\
B=\left[\begin{array}{cccccc}
\frac{X_{s s}}{\omega_{b}} & 0 & 0 & \frac{X_{M}}{\omega_{b}} & 0 & 0 \\
0 & \frac{X_{s s}}{\omega_{b}} & 0 & 0 & \frac{X_{s s}}{\omega_{b}} & 0 \\
0 & 0 & \frac{X_{l s}}{\omega_{b}} & 0 & 0 & 0 \\
\frac{X_{s s}}{\omega_{b}} & 0 & 0 & \frac{X_{r r}^{\prime}}{\omega_{b}} & 0 & 0 \\
0 & \frac{X_{s s}}{\omega_{b}} & 0 & 0 & \frac{X_{r r}^{\prime}}{\omega_{b}} & 0 \\
0 & 0 & 0 & 0 & 0 & \frac{X_{l r}^{\prime}}{\omega_{b}}
\end{array}\right]^{-1} .
\end{gathered}
$$

The expression for $A$ is given in (7).

TABLE VII

PARAMETERS OF THE SIMULATED DFIG IN NETWORK SYSTEM

\begin{tabular}{|c|c|}
\hline$X_{l s}(\Omega)$ & $0.09231 \mathrm{pu}$ \\
\hline$X_{M}(\Omega)$ & $3.95279 \mathrm{pu}$ \\
\hline$X_{l r}(\Omega)$ & $0.09955 \mathrm{pu}$ \\
\hline$R_{s}(\Omega)$ & $0.00488 \mathrm{pu}$ \\
\hline$R_{r}^{\prime}(\Omega)$ & $0.00549 \mathrm{pu}$ \\
\hline$H$ & $3.5 \mathrm{~s}$ \\
\hline
\end{tabular}

\section{REFERENCES}

[1] P. Kundur, Power System Stability and Control. McGraw-Hill Companies, 1994.

[2] K. P. Padiyar, Power System Dynamics Stability and Control. BS Publications, 2002. 
TABLE VI

TORSIONAL MODE AND NETWORK MODE AT VARIOUS WIND SPEEDS

\begin{tabular}{|c|c|c|c|c|c|c|c|}
\hline \hline \multirow{2}{*}{$\%$ Comp. } & \multirow{2}{*}{ Wind Speed } & \multicolumn{3}{|c|}{ Torsional Mode } & \multicolumn{3}{c|}{ Network Mode } \\
\cline { 2 - 8 } & & $\sigma \pm j \omega$ & $f_{T I}(H z)$ & $\xi$ & $\sigma \pm j \omega$ & $f_{s}-f_{n}(H z)$ & $\xi$ \\
\hline \multirow{3}{*}{$75 \%$} & $7 \mathrm{~m} / \mathrm{s}$ & $-0.4 \pm j 164.7$ & 26.2 & $0.24 \%$ & $-1.5 \pm j 177.1$ & 28.19 & $0.85 \%$ \\
\cline { 2 - 8 } & $8 \mathrm{~m} / \mathrm{s}$ & $-0.3 \pm j 162.8$ & 25.91 & $0.18 \%$ & $-2.1 \pm j 178.3$ & 28.38 & $1.18 \%$ \\
\cline { 2 - 8 } & $9 \mathrm{~m} / \mathrm{s}$ & $-0.4 \pm j 162.2$ & 25.81 & $0.25 \%$ & $-2.3 \pm j 178.8$ & 28.46 & $1.29 \%$ \\
\cline { 2 - 8 } & $10 \mathrm{~m} / \mathrm{s}$ & $-0.5 \pm j 162.0$ & 25.78 & $0.31 \%$ & $-2.5 \pm j 179.0$ & 28.49 & $1.40 \%$ \\
\hline \hline \multirow{3}{*}{$90 \%$} & $7 \mathrm{~m} / \mathrm{s}$ & $9.2 \pm j 158.8$ & 25.27 & $-5.78 \%$ & $-8.1 \pm j 159.6$ & 25.40 & $5.1 \%$ \\
\cline { 2 - 8 } & $8 \mathrm{~m} / \mathrm{s}$ & $6.2 \pm j 159.0$ & 25.31 & $-3.9 \%$ & $-8.1 \pm j 158.5$ & 25.22 & $5.1 \%$ \\
\cline { 2 - 8 } & $9 \mathrm{~m} / \mathrm{s}$ & $5.2 \pm j 158.9$ & 25.29 & $-3.27 \%$ & $-7.6 \pm j 158.4$ & 25.21 & $4.79 \%$ \\
\cline { 2 - 8 } & $10 \mathrm{~m} / \mathrm{s}$ & $4.7 \pm j 159.0$ & 25.31 & $-2.95 \%$ & $-7.4 \pm j 158.3$ & 25.19 & $4.67 \%$ \\
\hline \hline
\end{tabular}

$\left[\begin{array}{c}v_{q s}^{e} \\ v_{d s}^{e} \\ v_{0 s}^{e} \\ v_{q r}^{\prime e} \\ v_{d r}^{\prime e} \\ v_{0 r}^{\prime e}\end{array}\right]=\left[\begin{array}{ccc}r_{s}+\frac{p}{\omega_{b}} X_{s s} & \frac{\omega_{e}}{\omega_{b}} X_{s s} & 0 \\ -\frac{\omega_{e}}{\omega_{b}} X_{s s} & r_{s}+\frac{p}{\omega_{b}} X_{s s} & 0 \\ 0 & 0 & r_{s}+\frac{p}{\omega_{b}} X_{l s} \\ -\frac{p}{\omega_{b}} X_{M} & \frac{\omega_{e}-\omega_{r}}{\omega_{b}} X_{M} & 0 \\ -\frac{\omega_{e}-\omega_{r}}{\omega_{b}} X_{M} & \frac{p}{\omega_{b}} X_{M} & 0 \\ 0 & 0 & 0\end{array}\right.$

$A=-B\left[\begin{array}{c}r_{s} \\ -\frac{\omega_{e}}{\omega_{b}} X_{s s} \\ 0 \\ 0 \\ -\frac{\omega_{e}-\omega_{r}}{\omega_{b}} X_{M} \\ 0\end{array}\right.$

$\frac{\omega_{e}}{\omega_{b}} X_{s s}$
$r_{s}$
0
$\frac{\omega_{e}-\omega_{r}}{\omega_{b}} X_{M}$
0
0

TABLE VIII

PARAMETERS OF THE SHAFT SYSTEM

\begin{tabular}{|c|c|}
\hline$H_{1}$ & $0.9 \mathrm{~s}$ \\
\hline$H_{2}$ & $4.29 \mathrm{~s}$ \\
\hline$D_{1}$ & $0 \mathrm{pu}$ \\
\hline$D_{2}$ & $0 \mathrm{pu}$ \\
\hline$D_{12}$ & $1.5 \mathrm{pu}$ \\
\hline$K_{12}$ & $99.67 \mathrm{pu}$ \\
\hline
\end{tabular}

[3] D. Limebeer and R. Harley, "Subsynchronous resonance of single-cage induction motors," IEE Proc.-Electric Power Applications, pt. B, vol 128, no. 1, pp. 33-42, Jan. 1981.

[4] R. K. Varma, S. Auddy, and Y. Semsedini, "Mitigation of subsynchronous resonance in a series-compensated wind farm using FACTS controllers," IEEE Trans. Power Del., vol. 23, no. 3, pp. 1645-1654, 2008.

[5] A. Ostadi, A. Yazdani, and R. Varma, "Modeling and stability analysis of a DFIG-based wind-power generator interfaced with a seriescompensated line," IEEE Trans. Power Del., vol. 24, no. 3, pp. 15041514, Jul. 2009.

[6] L. F. C. Zhu and M. Hu, "Modeling and simulation of a dfig-based wind turbine for SSR," Proceedings of North American Power Symposioum (NAPS), Oct. 2009.

[7] F. de Jesus, E. Watanabe, L. de Souza, and J. Alves, "SSR and power oscillation damping using gate-controlled series capacitors (GCSC)," IEEE Trans. Power Del., vol. 22, no. 3, pp. 1806-1812, 2007.

[8] L. S. Kumar and A. Ghosh, "Modeling and control design of a static synchronous series compensator," IEEE Trans. Power Del., vol. 14, no. 4, pp. 1448-1453, Oct. 1999.

[9] IEEE Committee Report, "First benchmark model for computer simulation of subsynchronous resonance," IEEE Trans. Power and Apparatus Systems, vol. 96, no. 5, pp. 1565-1672, Sep./Oct. 1977.

[10] N. W. Miller, W. W. Price, and J. J. Sanchez-Gasca, "Dynamic modeling of ge 1.5 and 3.6 wind turbine-generators," GE-Power Systems Energy Consulting, General Electric International, Inc., Schenectady, NY, Oct. 2003.

$$
\left.\begin{array}{ccc}
\frac{p}{\omega_{b}} X_{M} & \frac{\omega_{e}}{\omega_{b}} X_{M} & 0 \\
-\frac{\omega_{e}}{\omega_{b}} X_{M} & \frac{p}{\omega_{b}} X_{M} & 0 \\
0 & 0 & 0 \\
r_{r}^{\prime}+\frac{p}{\omega_{b}} X_{r r}^{\prime} & \frac{\omega_{e}-\omega_{r}}{\omega_{b}} X_{r r}^{\prime} & 0 \\
-\frac{\omega_{e}-\omega_{r}}{\omega_{b}} X_{r r}^{\prime} & r_{r}^{\prime}+\frac{p}{\omega_{b}} X_{r r}^{\prime} & 0 \\
0 & 0 & r_{r}^{\prime}+\frac{p}{\omega_{b}} X_{l r}^{\prime}
\end{array}\right]\left[\begin{array}{c}
i_{d s}^{e} \\
i_{q s}^{e} \\
i_{0 s}^{e} \\
i_{q r}^{\prime e} \\
i_{d r}^{\prime e} \\
i_{0 r}^{\prime e}
\end{array}\right]
$$

Lingling Fan (S'99-M'02) received the BS, MS degrees in electrical engineering from Southeast University, Nanjing, China, in 1994 and 1997. She received Ph.D. degree in electrical engineering from West Virginia University in 2001. She is currently an assistant professor in Dept. of Electrical Engineering, University of South Florida (USF). Before joining USF, Dr. Fan was with North Dakota State University and Midwest ISO. Her research interests include modeling and control of energy systems, power system planning and operation.

Rajesh Kavasseri received his Ph.D. degree in Electrical Engineering from Washington State University, Pullman, WA in 2002. He is currently an associate professor in North Dakota State University. Dr. Kavasseri's research areas are power system dynamics and control, nonlinear system, algebraic geometry application in power system analysis. 
Zhixin Miao (S'00-M'03) received his BSEE from Huazhong University of Science \& Technology, Wuhan, China, in 1992. He received his MSEE from the graduate school of Nanjing Automation Research Institute in 1997 and $\mathrm{Ph} . \mathrm{D}$. in Electrical Engineering from West Virginia University. He is with University of South Florida. Prior to joining USF in 2009, he was with the transmission asset management department in Midwest ISO, St. Paul, Minnesota since 2002. His research interests include dynamics modeling of electric machinery and power system, power system protection, reliability and economics. 